\title{
Influence of Corrosion of Self-Piercing Riveted High Strength Aluminium Alloy Joints with Button Cracks on the Mechanical Strength
}

\author{
Dezhi Li $i^{1, *}$, Li Han ${ }^{3,4}$, Andreas Chrysanthou ${ }^{2}$ and Mike Shergold ${ }^{3,4}$ \\ ${ }^{1}$ WMG, University of Warwick, Coventry, CV4 7AL, UK \\ ${ }^{2}$ Department of Aerospace, Automotive and Design Engineering, University of Hertfordshire, AL10 9AB, UK \\ ${ }^{3}$ Jaguar Engineering Centre, Jaguar Land Rover, Coventry, CV3 4LF, UK \\ ${ }^{4}$ Now with Hansher Consulting Ltd
}

\begin{abstract}
For high strength aluminium alloys, such as AA6008T61 and AA6111 PFHT, when they are joined as the bottom material by self-piercing riveting (SPR), they tend to crack at the joint buttons. These cracks, especially those penetrated to the rivets, may cause galvanic corrosion problem with the steel rivet. In this paper, the mechanical strength of four stack/die combinations with different joint button cracking severity was studied before and after salt-spray corrosion test. The results showed that corrosion on the severely cracked joints was worse than that on the joints with small cracks and the corrosion on the stack with the same top and bottom material was less than that on the stack with different top and bottom materials. For all joints the static lap shear strength after corrosion was improved, but the static $T$ peel strength after corrosion was slightly reduced or did not have obvious change. The results also showed that after corrosion the lap shear fatigue strength of the specimens with severe cracks did not have obvious change, but the lap shear fatigue strength of the specimens with small cracks slightly reduced.
\end{abstract}

Keywords: SPR, High strength aluminium alloys, Lap shear, T peel, Fatigue, Corrosion.

\section{INTRODUCTION}

Aluminium alloys are used increasingly for automotive body structures to improve fuel efficiency and reduce greenhouse gas emissions. Currently, selfpiercing riveting (SPR) is a major technology used by manufacturers to join aluminium body structures due to its advantages, such as no pre-drilled holes and alignment needed, ability to join dissimilar materials, high static and fatigue strength and no surface treatment required. Research in this area has shown that self-piercing riveting of aluminium alloys gives joints of comparable static strength and superior fatigue behaviour to resistance spot welding [1-3].

Normally, for SPR of one specific stack, more than one die, rivet, and force combination can be applied. But it is not feasible to use the optimized parameter combination for every stack, which will be too expensive due to the number of robots and SPR systems required. In order to increase productivity and reduce cost, it is preferred to use the same rivet/die combination for as many joints as possible. As a result, some compromise may be made as to joint geometry and cracking when selecting a parameter combination

*Address correspondence to this author at the WMG, University of Warwick, Coventry, CV4 7AL, UK; Tel: +44 (0) 2476574614;

E-mail: dezhi.li@warwick.ac.uk for a stack and the chosen parameter combination will depend on the surrounding joints. This means for the same stack, different dies may be used with some as not optimized. It is important to find out whether a compromise is acceptable as to joint quality and performance in service.

Our research found that high strength aluminium alloys, such as AA6008T61 and AA6111 PFHT, tend to crack when they were used as the bottom material with some dies in SPR process. Since nowadays normally steel rivets are used to join aluminium structures, galvanic corrosion will occur at the exposed steel/aluminium interfaces. When cracks, especially those penetrated to rivets, are existing at the joint buttons, they will cause additional galvanic corrosion. Calabrese et al. [4] studied the influence of alternative immersion corrosion test on the lap shear strength of aluminium SPR joints, and their results showed that corrosion reduced the joint strength due to crevice and pitting corrosion. Calabrese et al. [5, 6] studied salt spray test on the mechanical performance of steel/aluminium hybrid SPR joints, and they demonstrated that corrosion influenced the failure mechanisms and significantly reduced the joint strength. The results also showed that the joints with thicker aluminium sheet had better mechanical stability during salt spray than those with thinner aluminium sheet. Mizukoshi and Okada [7] studied the influence of 
corrosion on the mechanical strength of the SPR aluminium alloy joints in salt spray. Their results showed that after corrosion the static lap shear strength of the SPR joints did not have obvious change but the fatigue lap shear strength decreased by about $30 \%$. Research from Chrysanthou [8] and loannou [9] showed that the lap shear strength of the SPR joint of steel and AA5182 initially increased until about $351 \mathrm{~h}$ and then started to reduce. Howard and Sunday [10] studied the effect of corrosion on the SPR joint strength by alternate immersion testing, and they found that following the corrosion, the lap shear strength of the AA5182/steel rivet joints and the AA6061/steel rivet joints was similar to or better than the strength before corrosion. But there is few literature reporting the influence of cracking on the corrosion resistance of SPR joints.

To see the influence of cracks on the corrosion resistance and joint strength, in this study a DF die that would generate severe cracks and a DC die that would only generate small cracks, were used to join two stacks with a high strength aluminium alloy, AA6008T61, as the bottom material. The joint quality of these specimens was analyzed, and the influence of corrosion on their static and fatigue strength were studied.

\section{EXPERIMENTS}

\subsection{Materials}

$2.5 \mathrm{~mm}$ thick AA5754 with a yield strength of 110 $\mathrm{MPa}$ and $2.5 \mathrm{~mm}$ thick AA6008T61 with a yield strength of $250 \mathrm{MPa}$ were used in this study. The AA5754 has a standard PT2 ALO70 surface condition; whilst the AA6008 has mill finished surface. Their compositions are listed in Table 1, and their stress-strain curves obtained from standard dog-bone tensile test are presented in Figure 1.

\subsection{JOINT FEATURE ANALYSIS}

For all stacks, steel rivets with a countersunk head and mechanical zinc/tin surface coating were used. The rivets were supplied by Henrob Ltd (part of Atlas
Copco group), and all specimens were produced using a Henrob Ltd servo-driven riveting equipment. $7 \mathrm{~mm}$ long rivets with a stem diameter of $5.3 \mathrm{~mm}$, and two different dies, the DF die and the DC die, were used. The rivets have a semi-tubular shape with countersunk head, as shown in Figure 2, and they are mechanically zinc/tin coated with thickness of around $12 \mu \mathrm{m}$. To comply with different material strength, rivets with a hardness of $\sim 555 \mathrm{Hv}$ and $\sim 480 \mathrm{Hv}$ were used for the $(2.5+2.5) \quad$ AA6008T61 stack and the 2.5AA5754+2.5AA6008T61 stack, respectively, and various riveting forces were applied to achieve proper rivet head height. The profiles of the DF and the DC dies are presented in Figure 3.

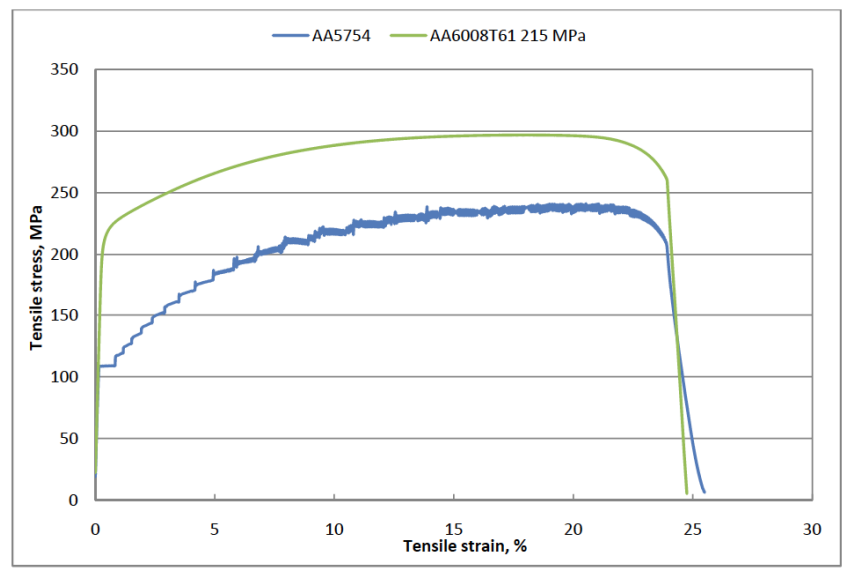

Figure 1: Tensile test results for the material used for this study.

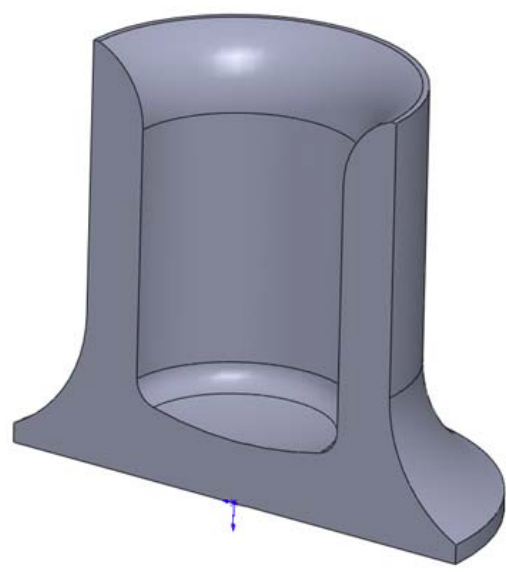

Figure 2: A cross-section of a Henrob rivet.

Table 1: Nominal Compositions of AA6008 and AA5754 (Balance Al)

\begin{tabular}{|c|c|c|c|c|c|c|c|c|c|c|}
\hline & Mg & Mn & Cu & Fe & Si & Ti & Cr & Zn & V Others \\
\hline \hline AA6008 & $0.4-0.7$ & $0-0.3$ & $0-0.3$ & $0-0.35$ & $0.5-0.9$ & $0-0.1$ & $0-0.3$ & $0-0.2$ & $0.05-0.2$ & $0-0.15$ \\
\hline AA5754 & $2.6-3.6$ & $0-0.5$ & $0-0.1$ & $0-0.4$ & $0-0.4$ & $0-0.15$ & $0-0.3$ & $0-0.2$ & - & $0-0.15$ \\
\hline
\end{tabular}




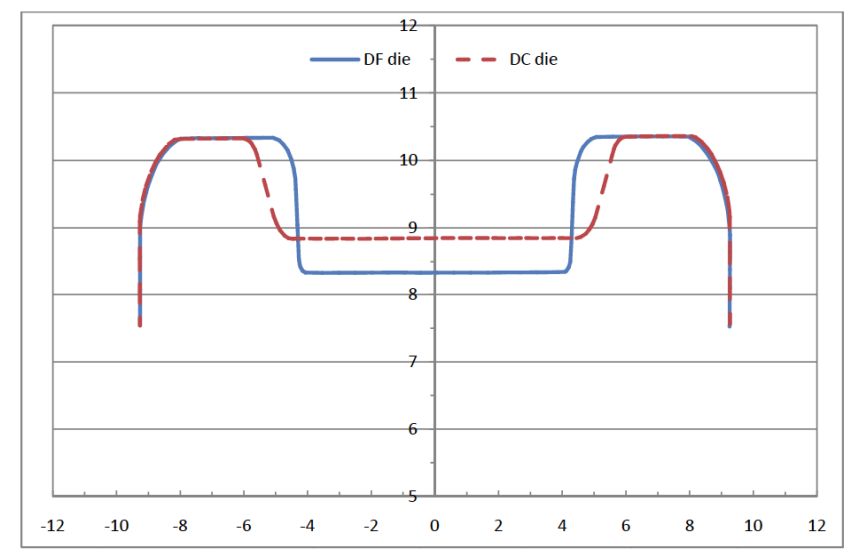

Figure 3: Scanned die profiles for the DF and DC dies.

All specimens were produced using custom designed fixtures to reduce any variations of rivet position. A special fixture was also used to ensure all joints were vertically cross-sectioned across the center of the rivets. Following sectioning, the joint features were measured and analyzed with respect to rivet head height, interlock and minimum remaining bottom material thickness using the a4i image analysis software.

\subsection{Corrosion tests}

The salt-spray corrosion test was performed according to the ASTM B117 standard, at $35{ }^{\circ} \mathrm{C}( \pm 1.5$ ${ }^{\circ} \mathrm{C}$ ) in a salt-spray chamber using a $5 \% \mathrm{NaCl}$ solution in distilled water. Firstly, the specimens were cleaned using a soft brush followed by treatment in an ultrasonic bath filled with acetone to remove any grease. The specimens were then cleaned with water and thoroughly dried by blowing hot air for $5 \mathrm{~min}$. They were subsequently left to rest for $48 \mathrm{~h}$ before weighing to an accuracy of four decimal places. The corrosion test was carried out in hourly cycles. This involved the specimens being subjected to a fog spray (salt spray) for $10 \mathrm{~m}$ at a flow rate of $0.8 \mathrm{l} / \mathrm{h}$ followed by $50 \mathrm{~min}$ of hot air (drying). The sequence was repeated every hour. Specimens were removed after approximately $1000 \mathrm{~h}$ for weight measurement and analysis after they were cleaned in an ultrasonic bath using distilled water to remove $\mathrm{NaCl}$ residuals, washed with propan-2-ol, and dried at $70^{\circ} \mathrm{C}$ in an oven.

\subsection{Mechanical tests}

For all mechanical tests, single-rivet specimens were used. Figure 4 shows the dimensions of the static and fatigue lap shear tests specimen. Figure $\mathbf{5}$ shows the dimension of the static $T$ peel specimen. During the preparation of specimens, coupons were cut from sheet such that the longitudinal direction of coupons coincides with the rolling direction of sheet metal. Single joint SPR specimens were then made using the custom fixture with the DF and DC dies. Both stacks, $(2.5+2.5)$ AA6008T61 and 2.5AA5754+2.5AA6008T61 were used for static lap shear test before and after corrosion, and the stack of 2.5AA5754+2.5AA6008T61 was also used for fatigue lap shear tests before and after corrosion.

Static lap shear and $\mathrm{T}$ peel tests were performed using a standard Instron tensile test machine at a 10 $\mathrm{mm} / \mathrm{min}$ cross-head speed. The grip distance for the static tests was $40 \mathrm{~mm}$, and that for the fatigue test was $80 \mathrm{~mm}$. In order to eliminate the initial secondary bending and to ensure alignment of the load paths, spacers with the corresponding thicknesses were used at both ends of the static lap shear specimens. Custom designed aluminium light grips were used for fatigue tests to increase fatigue machine's response speed. These grips were specially designed for lap shear fatigue tests so that the two fixed jaws (in opposite
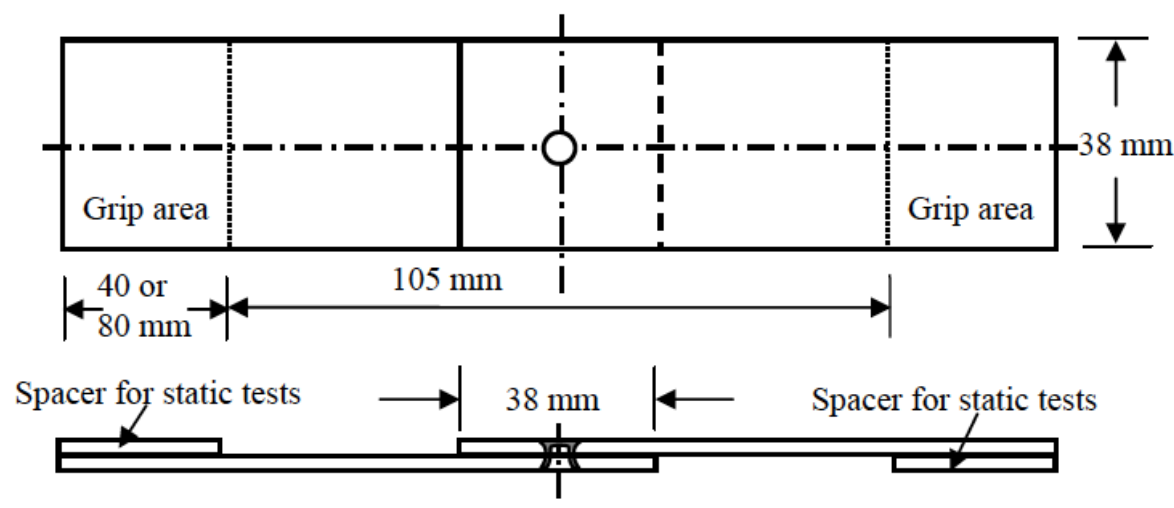

Figure 4: Specimen geometry and dimensions for static and fatigue lap shear tests (grip distance: static, $40 \mathrm{~mm}$; fatigue, 80 $\mathrm{mm})$. 


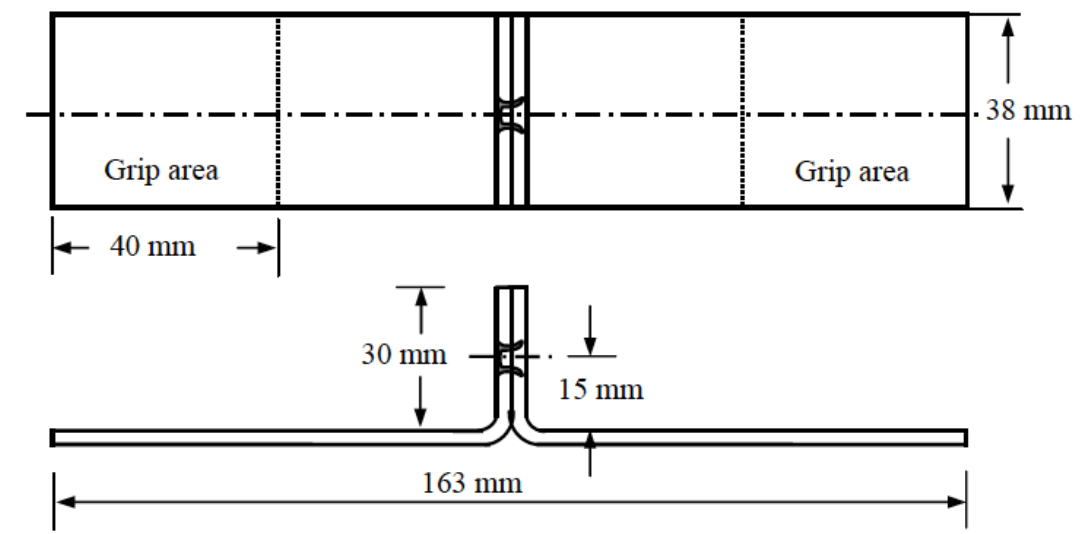

Figure 5: Specimen geometry for static $T$ peel tests.

sides) in the upper and lower grips were aligned along the joint interface and no additional spacers are needed to eliminate the initial secondary bending. Load-controlled fatigue tests were performed on a close-loop servo hydraulic testing machine using a sinusoidal wave form and in tension-tension mode. The ratio of the minimum load and the maximum load or $\mathrm{R}$ ratio was 0.1 and the test frequency was $15 \mathrm{~Hz}$ in all the tests. Three or four load levels which had different values of the maximum load were tested. The values of the maximum loads were about $30 \%$ to $80 \%$ of the maximum loads obtained from static tests. Test criterion was fracture of the specimens. At least 3 specimens were tested at each condition.

\section{RESULTS AND DISCUSSION}

\subsection{Joint Quality}

Due to the different constraints applied to substrate materials, when dies with different profiles are used, the joints will have different features. Figures 6 and 7 compared the features of the joints produced with the DF and DC dies from the stacks $(2.5+2.5)$ AA6008T61 and 2.5AA5754+2.5AA6008 T61, respectively. Figure 6 showed that the vertical sections revealed that the joint produced with the DF die had $-0.05 \mathrm{~mm}$ head height, $0.52 \mathrm{~mm}$ interlock (average value for all interlocks) and $0.5 \mathrm{~mm}$ remaining material thickness and the joint

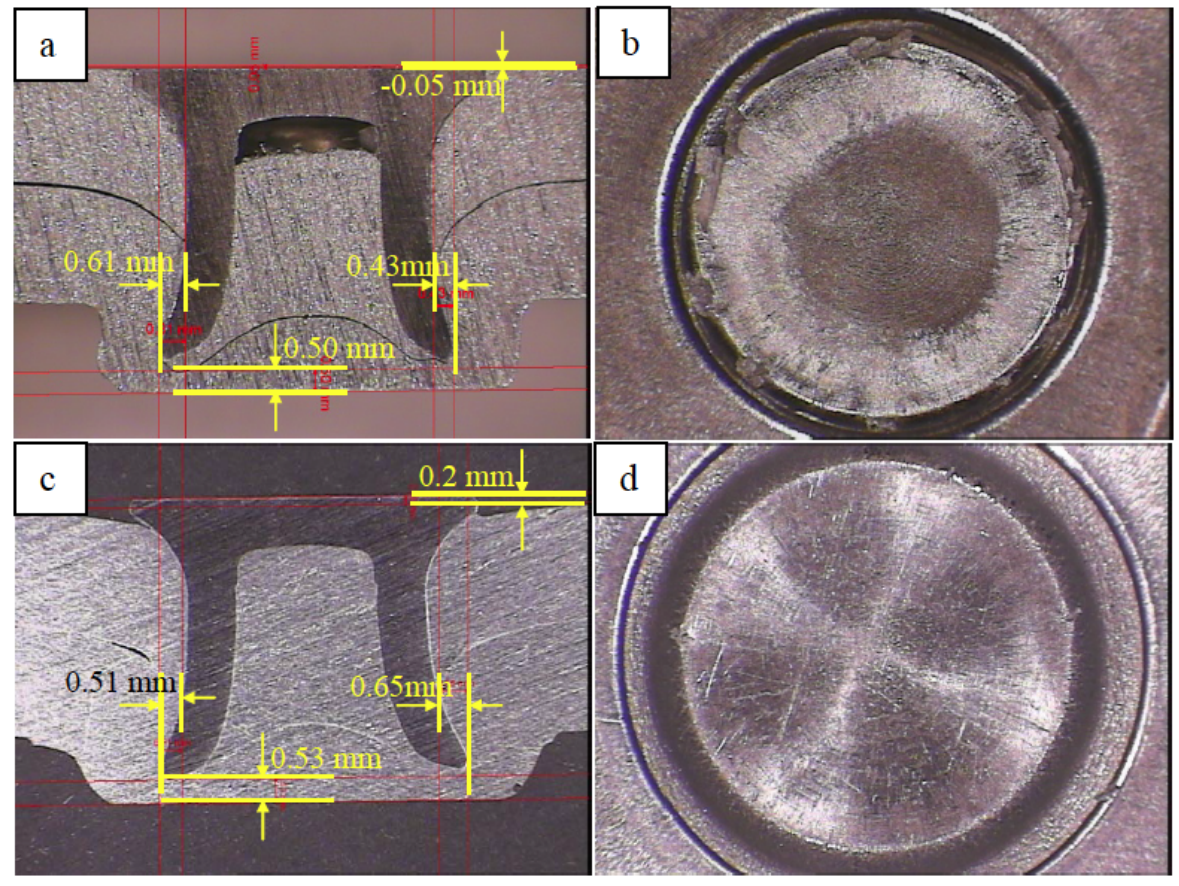

Figure 6: Cross-sections and joint button images of SPR joints for stack (2.5+2.5) AA6008T61 $250 \mathrm{MPa}$ with, a) b) the DF die and c) d) the DC die. 


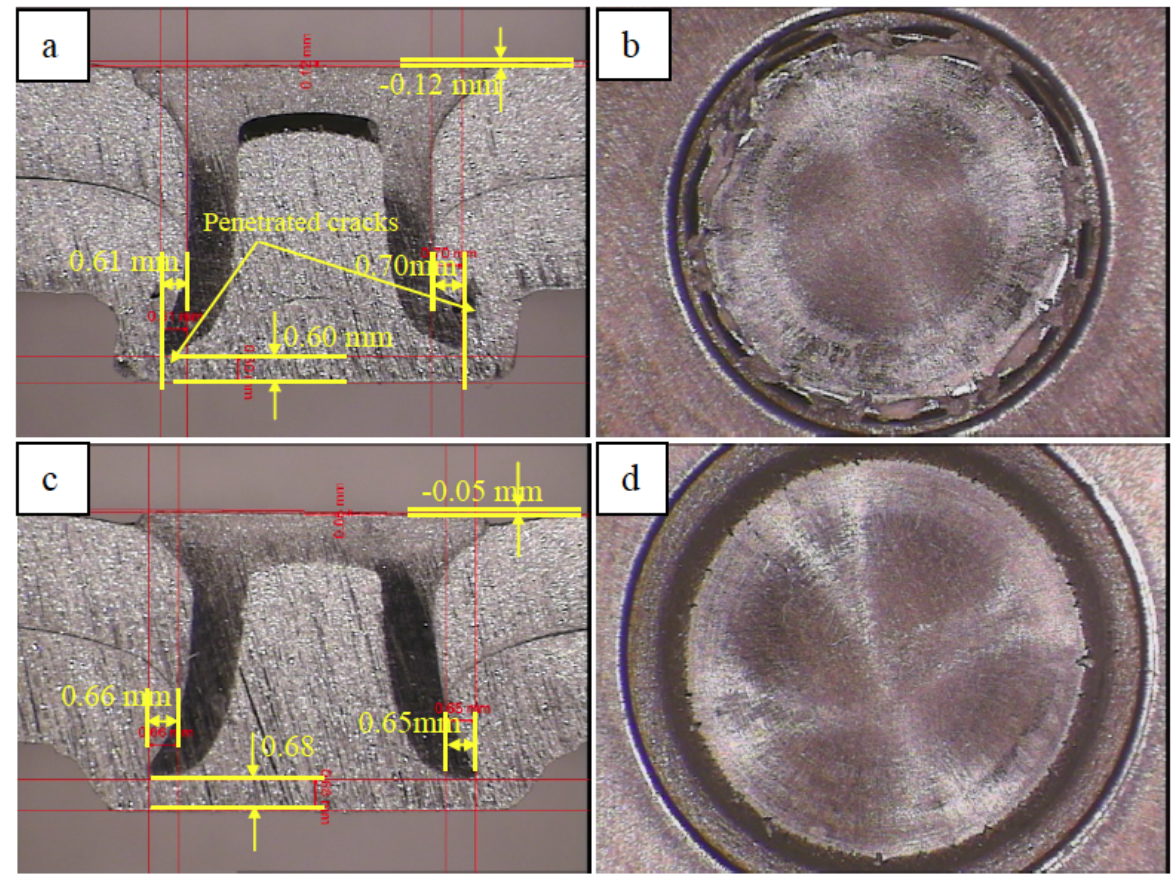

Figure 7: Cross-sections and button images of SPR joints for stack 2.5AA5754+2.5AA6008 T61 $250 \mathrm{MPa}$ with, a) b) the DFdie and c) d) the DC die.

produced with the DC die had $0.2 \mathrm{~mm}$ head height, $0.58 \mathrm{~mm}$ interlock and $0.53 \mathrm{~mm}$ remaining material thickness. According to the SPR quality criteria, both joints were good joints as to interlocks. However, the joint produced with the DF die failed by the existing of severe cracks on the joint button (crack depth up to 0.5 $\mathrm{mm}$, but did not reach the rivet), which may cause galvanic corrosion. In contrast, the joint produced with the DC die only several minor cracks on the joints button.

Figure 7 shows the cross sections and button images of the joints from stack 2.5AA5754+2.5AA6008 T61. The vertical sections revealed that the joints produced with the DF and DC dies had similar average interlock $(0.66 \mathrm{~mm})$, but the joint with the DC die had thicker bottom remaining material thickness $(0.68 \mathrm{~mm})$ than that with the DF die $(0.60 \mathrm{~mm})$. From the joint button images in Figure $\mathbf{7 b}$ and $\mathbf{d}$, it can be seen that similarly to the joints from stack $(2.5+2.5)$ AA6008T61, the joint from stack 2.5AA5754+2.5AA6008 T61 with the DF die had much more severe cracks than that with the $D C$ die. In fact, the cracks in the joint from stack 2.5AA5754+2.5AA6008 T61 with the DF die were the worst among the four stack/die combinations, and a lot of those had penetrated into the rivet/bottom sheet interface.

This difference of joint feature can be explained by the difference of die profiles as shown in Figure 3.
From the die profiles, it can be seen that compared with the DF die, the DC die has a larger diameter, a lower depth and a tilted sidewall. As a result, for joints produced with the DF die, the bottom layer underwent large deformation equivalent to a deep drawing process; for joints produced with the DC die, the bottom layer had less stress concentration and underwent less deformation. Because the DC die had a lower depth and the rivets used for the two joints produced with the DF and DC dies had the same length, the rivet in the joint produced with the DC die would had larger constraint and flare more during the SPR process. When compare the stack $(2.5+2.5)$ AA6008T61 with the stack 2.5AA5754+ $2.5 A A 6008 T 61$, it can be seen that the cracking on the joints from the stack 2.5AA5754+2.5AA6008 T61 was more severe. This may be caused by the larger flare of rivets in the joints from 2.5AA5754+2.5AA6008T61 stack. AA5754 is softer than AA6008T61, so the rivets used in 2.5AA5754+2.5AA6008T61 stack were softer than that used in $(2.5+2.5)$ AA6008T61, and during a SPR process, the rivets in the joints from 2.5AA5754+ 2.5AA6008T61 stack would flare more and cause larger stress concentration at joint buttons, resulting in more severe cracks.

\subsection{Static Strength}

Figure 8 shows the lap shear strength of single-rivet specimens of the $(2.5+2.5)$ AA6008T61 stack and the 
2.5AA5754+2.5AA6008T61 stack produced with two different dies before and after corrosion. It can be seen that for the $(2.5+2.5)$ AA6008T61 stack, the lap shear strength of the specimens with the DF die and the DC die were similar before corrosion, and after corrosion the lap shear strength of the specimens with the both dies increased, but the lap shear strength of the specimens with the DF die increased more than that of the specimens with the DC die. For 2.5AA5754+2.5AA6008T61 stack, the lap shear strength of the specimens with the DF die was slightly higher than that of the specimens with the DC die, and after corrosion the change of the lap shear strength was similar with that for $(2.5+2.5)$ AA6008T61 stack. The increase amount of lap shear strength of the specimens with the DF die was much higher than that of the specimens with the DC die. It is believed that the corrosion products between the top and bottom materials and between rivet and sheet materials caused the increase of lap shear strength after corrosion. However, after further corrosion, due to the reduction of sheet material strength, the lap shear strength of these specimens will start to drop. These results are consistent with the research from loannou [9], in which the lap shear strength of specimens from a steel/Al stack increased after corrosion in salt spray chamber for 351 hours and then greatly reduced when corroded for about 660 hours.
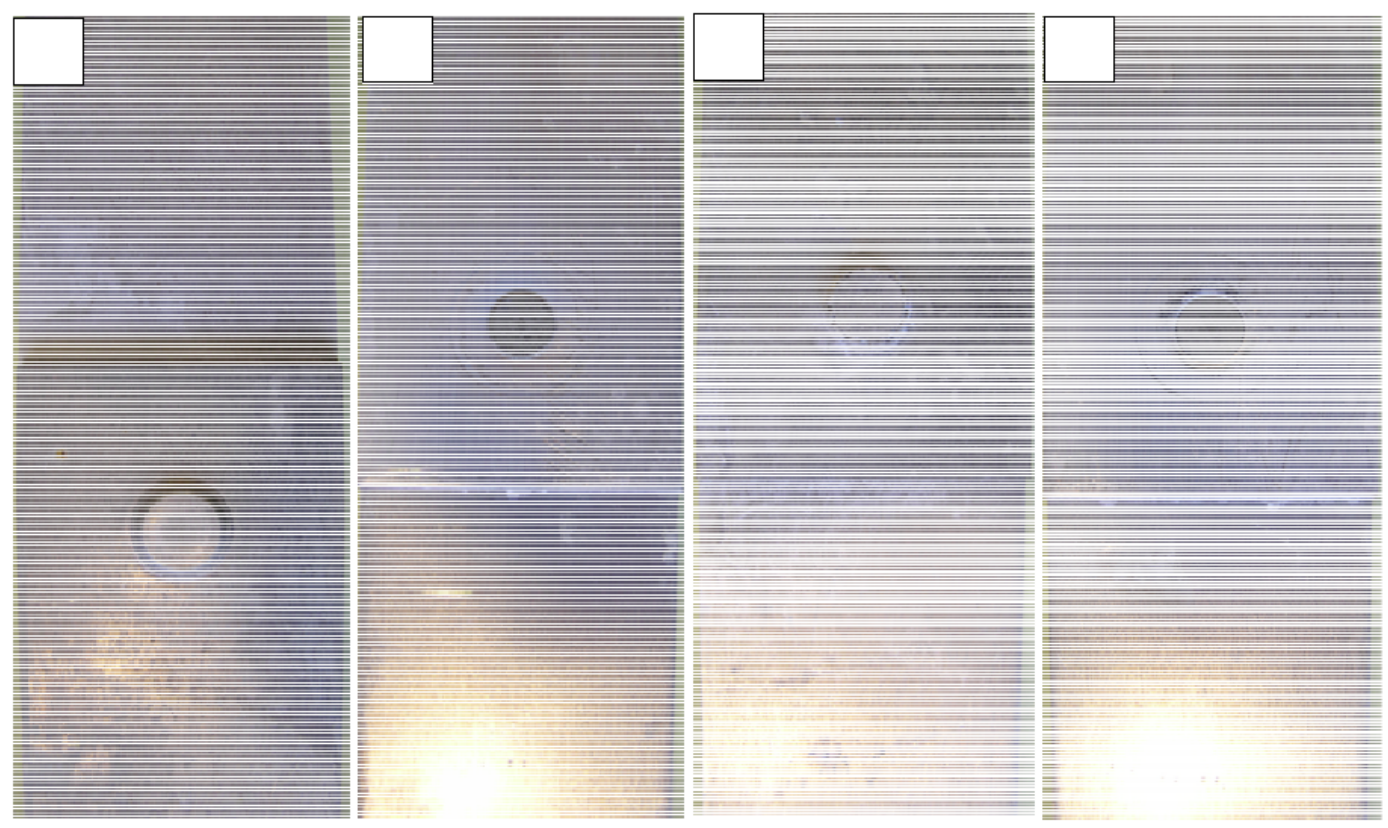

Figure 9: Lap shear specimens for the stack of 2.5AA5754+2.5AA6008T61 after corrosion, a) bottom view, the DC die, b) top view, the DC die, c) bottom view, the DF die and d) top view, the DF die. AA6008T61 and 2.5AA5754+2.5AA6008T61 stacks before and after corrosion.

Figure 9 shows the appearance of the lap shear specimens for the stack of 2.5AA5754+2.5AA6008T61 after corrosion. It can be seen that apart from the area around the severely cracked joint button of the specimen with the DF die, the corrosion on the other parts of the specimens are benign.

Figures 10 and 11 show the static lap shear fracture interfaces of the specimens from the $(2.5+2.5)$ AA6008T61 stack and the 2.5AA5754+2.5 AA6008T61 stack produced with two different dies before and after corrosion, respectively. Compared with Figure 9, it can be seen that the overlapped area between the top and

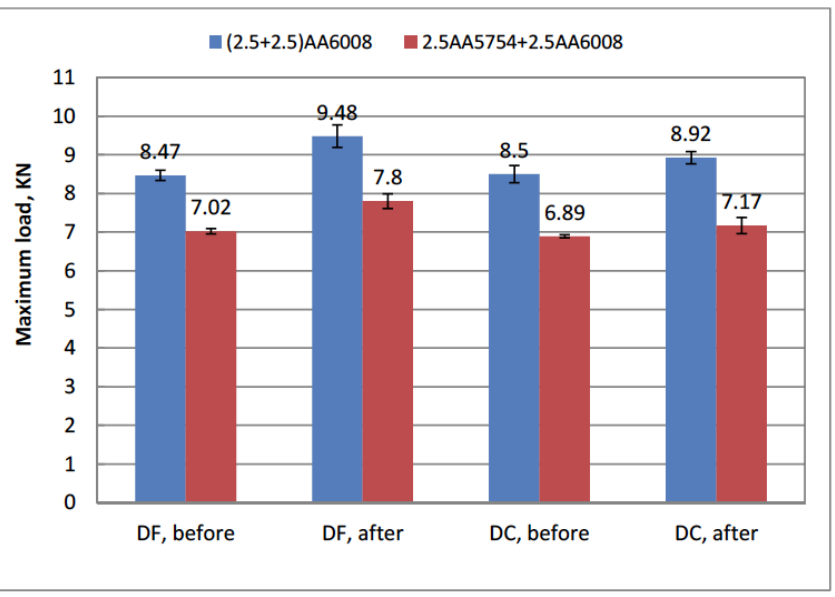



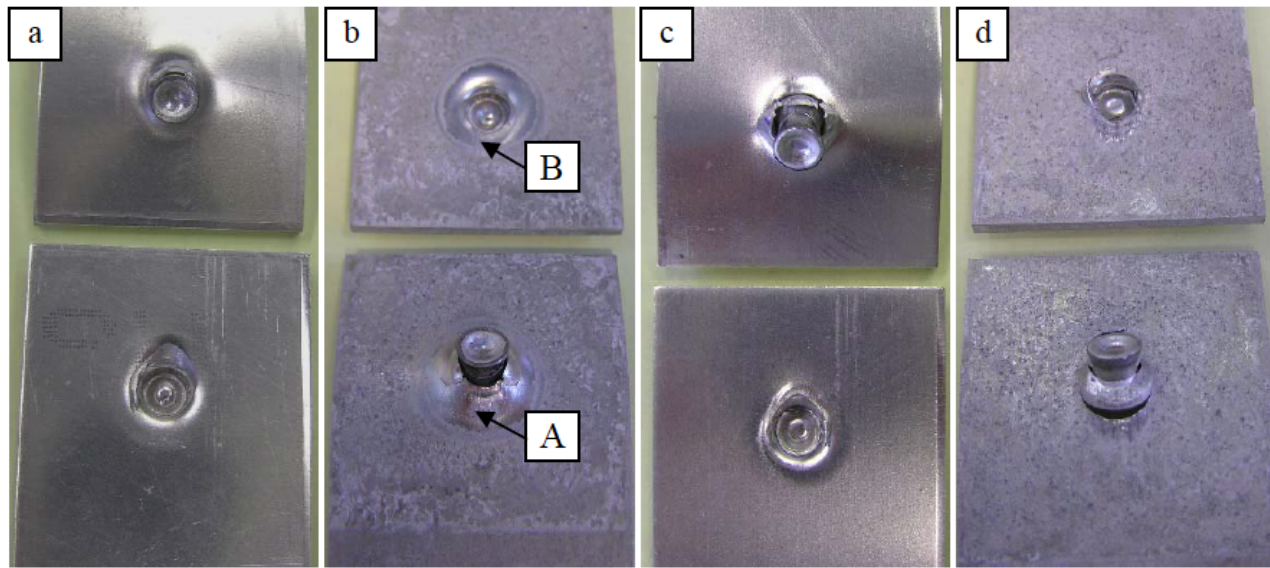

Figure 10: Static lap shear fracture interfaces for the stack of $(2.5+2.5)$ AA6008T61, a) with the DC die before corrosion, b) with the DC die after corrosion, c) with the DF die before corrosion and d) with the DF die after corrosion.
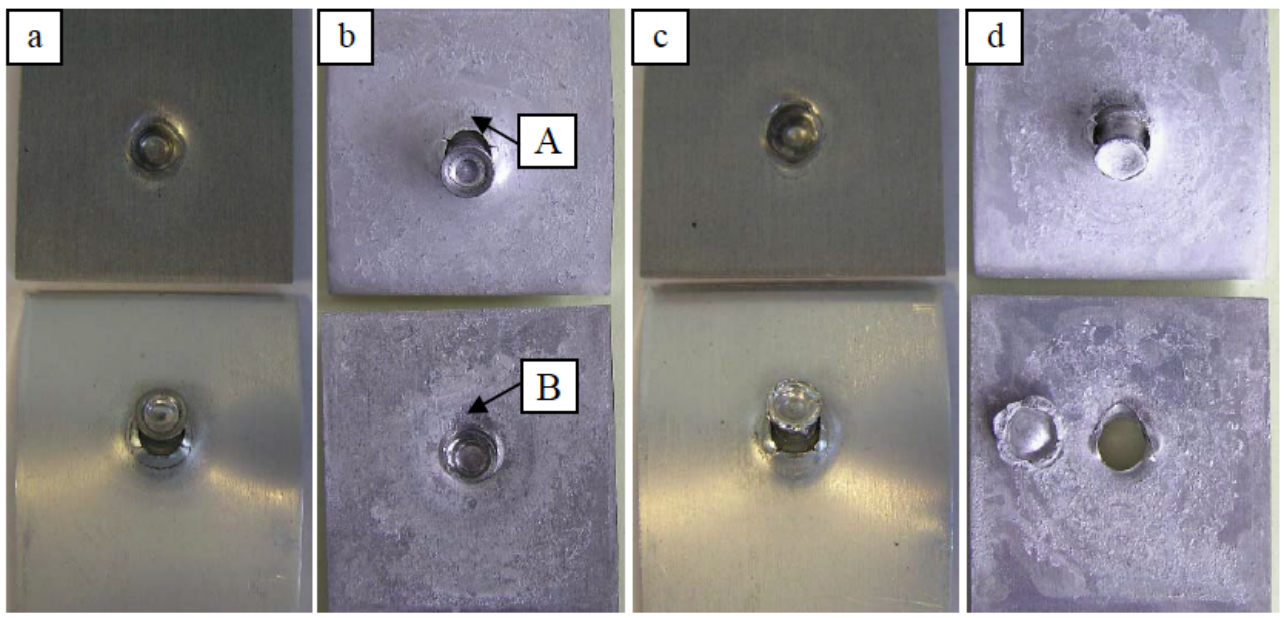

Figure 11: Static lap shear fracture interfaces for the stack of 2.5AA5754+2.5AA6008T61, a) with the DC die before corrosion, b) with the DC die after corrosion, c) with the DF die before corrosion and d) with the DF die after corrosion.

bottom sheets had more corrosion products than the other areas due to crevice corrosion. For specimens of both stacks with the DC die, before and after corrosion, the lap shear failure mode did not have obvious difference (Figure 10 a, b and Figure 11 a, b). But for specimens with the DF die, before and after corrosion, the failure mode was slightly different. For the specimens of the $(2.5+2.5)$ AA6008T61 stack with the DF die, although for both before and after corrosion rivets were pulled out from bottom sheets for all specimens, during the static lap shear test after corrosion, a ring of material from the top sheet underneath the rivet head was pulled out as shown in Figure 10d, which may be caused by the galvanic corrosion between the rivet head and the top sheet material around it. From Figure $\mathbf{6 a}$, it can be seen that in the joint of $(2.5+2.5)$ AA6008T61 stack with the DF die the rivet head was in close contact with the top sheet and the rivet head was about $0.05 \mathrm{~mm}$ below the top surface of the top sheet. The penetration of rivet head will weaken the strength of top sheet around the punched hole. Since the potential for the zinc/tin coated steel rivet is more negative than that for the sheet (Al alloy), during corrosion tests the zinc/tin coating on the rivet surface would be corroded first; however, after the complete consumption of this coating, the steel would be exposed to the corrosion media. Because Al has a more negative corrosion potential than steel, Al sheet around the rivet head would start to be corroded. It is believed that the corrosion of top sheetcaused the pullout of the ring of material underneath the rivet head, and the penetration of rivet head into the top sheet may accelerate the corrosion of top sheet material around the rivet head.

Figure $10 \mathbf{b}$ and $\mathbf{d}$ show that during corrosion test the top and bottom AA6008T61 at the joint interfaces were corroded with a lot of corrosion products on the 
surfaces. It can be seen that the partially pierced hole in the bottom sheet and the rivet tails did not have obvious corrosion. Although for the joints with DF die, there were cracks on the joint buttons, these cracks did not penetrate to the rivet tail, and as a result corrosion media could not get into the partially pierced hole and rivet interface. This galvanic corrosion would have happened to the specimens from the other 3 stack/die combinations, but because their failure strength was lower, it was not high enough to pull-out the ring of material in the top sheet, or because there was a weaker link at other place, such as pulling the rivet out from the top sheet.

From Figure $11 \mathrm{~b}$ and $\mathbf{d}$, it can be seen that the materials at the joint interfaces between the top AA5754 sheet and the bottom AA6008 sheet in the 2.5AA5754+2.5 AA6008T61 joints had more severe corrosion than the materials at the joint interfaces of the $(2.5+2.5)$ AA6008T61joints, with much more corrosion products at the interfaces. Sincethe AA5754 and AA6008 alloys have different corrosion potentials, itwill cause galvanic corrosion between them in addition to the corrosion between the rivet and the substrate materials. For the 2.5AA5754+2.5 AA6008T61 joints with the DF die, cracks in the joint button penetrated into rivet tail as shown in Figure $\mathbf{7} \mathbf{a}$ and $\mathbf{b}$, so during corrosion tests corrosion media will penetrate into the rivet and the bottom partially pierced hole interface. From Figure 11d, it can be seen that the zinc/tin coated rivet, the AA5754 material punched inside the rivet cavity and the AA6008T61 joint buttons were all corroded. Due to the existing of cracks and subsequent corrosion, the joint button wasbroken during the static lap shear tests. The corrosion of Almay happen after the consumption of the zinc/tin coating on the rivet tail.

Since SPR is a mechanical joining process, any corrosion product between rivet and sheet material will make the joint tighter, and as a result the joints after corrosion will be able to sustain more load. For lap shear strength of SPR joints, frictions at the top and bottom material interface, the rivet head and the top material interface, and the rivet tail and the bottom material interface are big contributors. Among these three frictions, which ones are more important will be determined by the failure modes: the friction at the rivet head and the top material interface is more important for rivet being pulled out from the top sheet, and the friction at the rivet tail and the bottom material interface is more important for rivet being pulled out from the bottom sheet. As to the friction at the top and bottom materials interface, it is important for all rivet pulling out failure modes, and it is the friction around the tip of the punched hole in the top sheet that is the most important. The influence of local friction on the lap shear strength of SPR joints was initially raised by Li et al. [11] when they were studying the influence of fatigue on the static joint strength. They found out that lap shear fatigue increased the remaining static lap shear strength of SPR joints during the fatigue duration: shortly after fatigue started until shortly before fatigue failure. They believed that the increase of lap shear joint strength was mainly caused by the increase of friction force between the tip of the punched hole in the top sheet and the edge of the partially pierced hole in the bottom sheet, due to the increased surface roughness by fatigue fretting. Later research from $\mathrm{Li}$ et al. [12] on the influence of different sheet material surface texture, from grit blasting, sandpaper grinding, hot tap water washing,and original surface with solid wax lubricant, on joint strength. They confirmed that the SPR joints with material of higher surface friction had higher static lap shear strength. Further research from $\mathrm{Li}$ et al. [13] confirmed that the critical location of friction influence on lap shear strength was between the top and bottom sheet around the tip of the punched hole in the top sheet.By studying the influence of local pin impression with garnet particles (with different ring sizes around the rivet piercing location) on static lap shear strength of SPR joints, they proved that the impression with the smallest ring and garnet particles (right around the tip of the punched hole in the top sheet) increased the lap shear strength the most and the strength increase could be up to $16 \%$.

It is believed that the corrosion products will increase the frictions at the three interfaces mentioned above and subsequently increase the lap shear strength. Some of the research on the influence of corrosion on the SPR joint strength has been reviewed by Li et al [14]. Since the 2.5AA5754+2.5 AA6008T61 joints with the DF diehad severe cracks, which penetrated into the rivet tail, corrosion media can penetrate into the rivet tail/bottom material interface more easily through cracks and cause corrosion between rivet tail and bottom material.However, for the 2.5AA5754+2.5 AA6008T61 joints with the DC die, since the cracks at the joint button were not penetrated into the rivet tail, there would be much less corrosion at the rivet tail/bottom material interface. From Figures 10 and 11, it can be seen that for both $(2.5+2.5)$ AA6008T61 and 2.5AA5754+2.5 AA6008T61 stacks, the local areas around rivets were smoother and the corrosion products around rivets were less for the joints 
with the $D C$ die than those for the joints with the DF die. As a result, for the 2.5AA5754+2.5 AA6008T61 stack, the increase of lap shear strength for the specimens with the DF die will be larger than that for the specimens with the DC die, due to higher tightness and higher local friction forces. Fracture interfaces after static lap shear tests showed that the main fretting at the top and bottom material interface happened at the interface between the tip of the punched hole from the top sheet and the edge of the partially pierced hole in the bottom sheet, as marked in Figures $10 \mathrm{~b}$ and $11 \mathrm{~b}$ as $\mathbf{A}$ and $\mathbf{B}$, respectively.

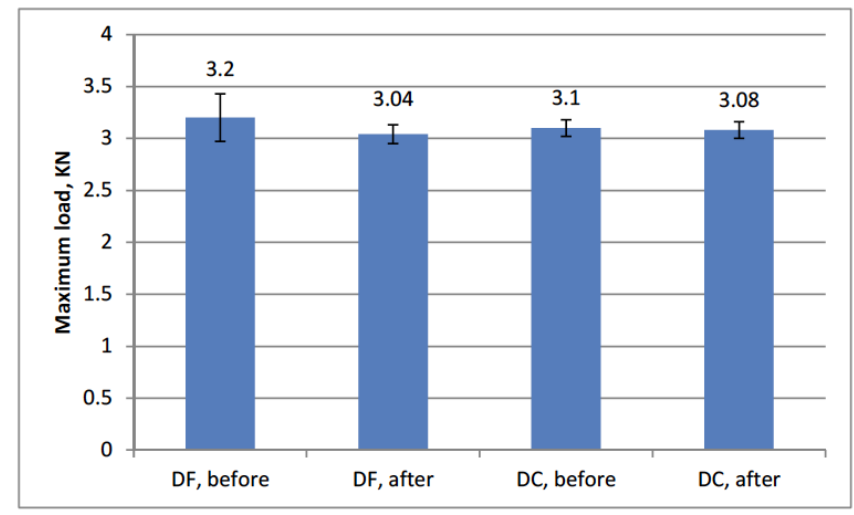

Figure 12: $T$ peel strength of single joint from the $(2.5+2.5)$ AA6008T61 stack.

Figure 12 shows the $T$ peel strength of single-rivet specimens of the $(2.5+2.5)$ AA6008T61 stack produced with two different dies before and after corrosion, respectively. It can be seen that specimens with the DF die had higher T peel strength than specimens with the DC die before corrosion tests. After corrosion tests the $T$ peel strength of the specimens with the DF die decreased, but the $T$ peel strength of the specimens with the DC die did not have obvious change.

Figure 13 shows the $T$ peel fracture interfaces for the stack of $(2.5+2.5)$ AA6008T61. It can be seen that the specimens with the DF die could fail by rivet being pulled out from the top or bottom sheet, but all the specimens with the DC die failed by rivet being pulled out from the bottom sheet. For the specimens with the DF die before corrosion, the specimens failed by rivet being pulled from top sheet had larger strength than those failed by rivet being pulled out from bottom sheet. As a result, the $T$ peel strength of the specimens with the DF die before corrosion had a larger deviation. However it was noticed that compared with the T peel strength of specimens before corrosion, the strength of the specimens failed by rivet being pulled out from bottom sheet did not have obvious change, but the strength of the specimens failed by rivet being pulled out from the top sheet reduced, resulting in a smaller deviation. This confirmed that the corrosion on the top AA6008T61 material weakened its strength, and as a result rivets could be more easily pulled out from it.

Due to the loading direction, the contact force at the top and bottom material interface during the $T$ peel tests was much lower than that in the lap shear tests, and as a result the friction between the top and bottom materials at the joint interface was much smaller and

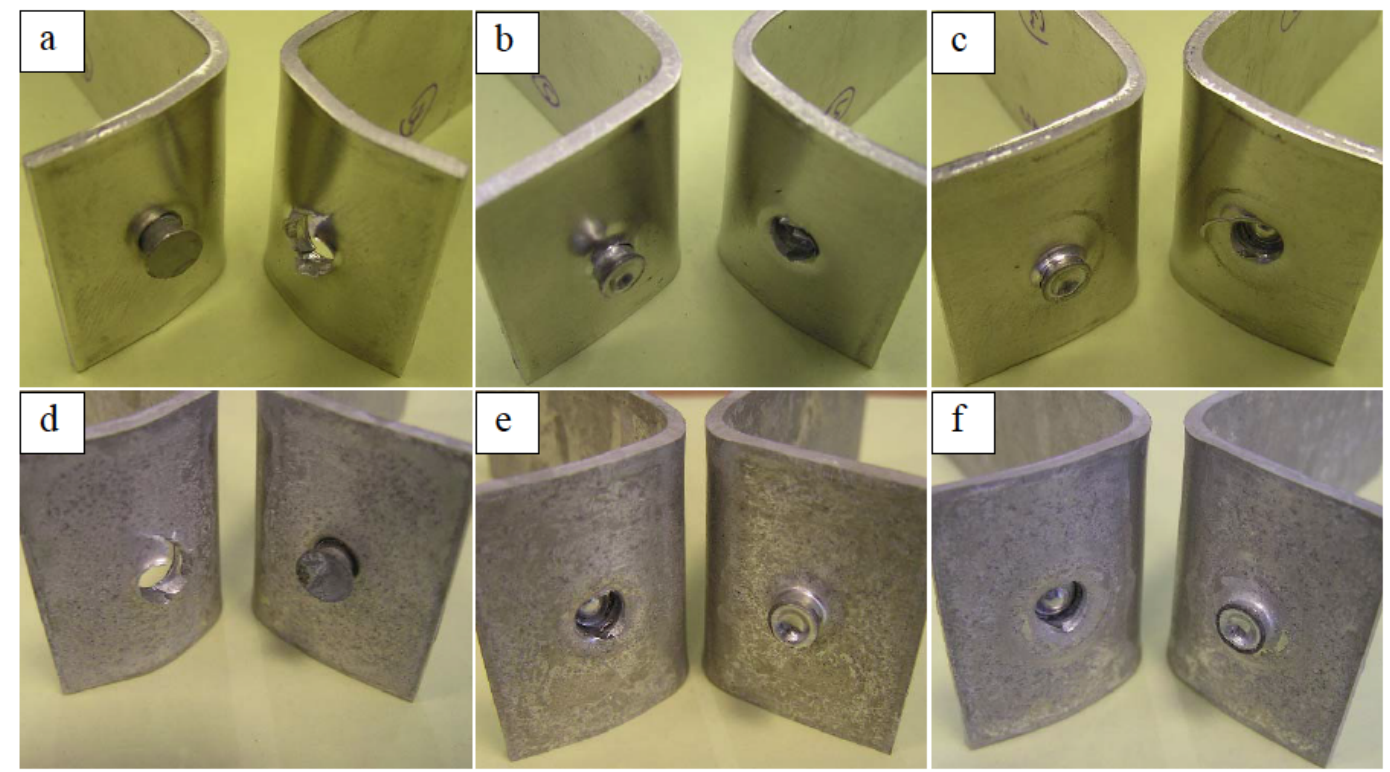

Figure 13: Static T peel fracture interfaces for the stack of $(2.5+2.5)$ AA6008T61, a) b) with the DF die before corrosion, c) with the DC die before corrosion, d) e) with the DF die after corrosion and f) with the DC die after corrosion. 
much less important to the $T$ peel joint strength. Consequently, the corrosion products at the top and bottom material interface did not have obvious influence on the friction and subsequently the $T$ peel strength.

\subsection{Fatigue Strength}

Figure 14 shows the Lap shear fatigue S-N curves of the 2.5AA5754+2.5 AA6008T61 stack before and after corrosion. It can be seen that for the specimens with the DF die their fatigue strength did not have obvious change after corrosion, but for the specimens with the DC die after corrosion their fatigue strength was slightly reduced.

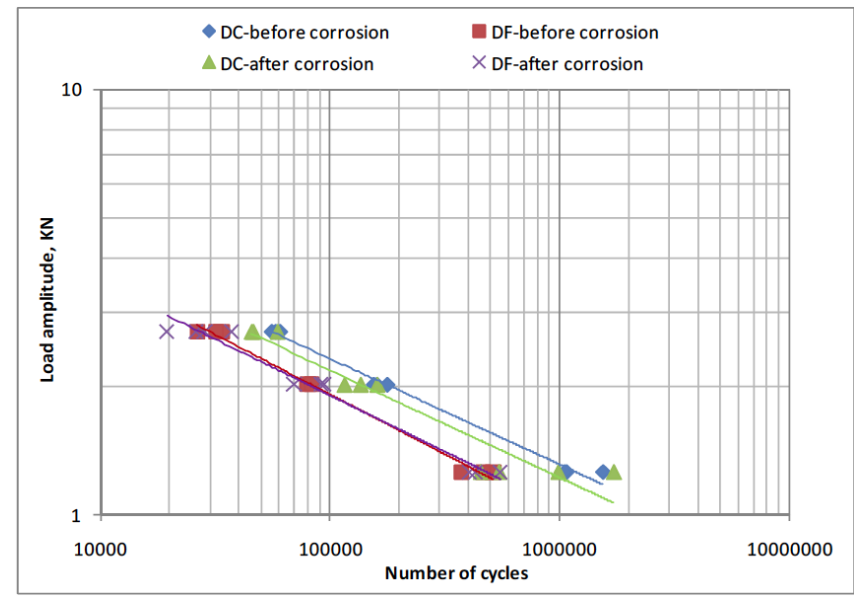

Figure 14: Lap shear fatigue $S-N$ curves of the 2.5AA5754+2.5 AA6008T61 stack before and after corrosion.

Figures 15 and 16 show the representative lap shear fatigue fracture interfaces for the 2.5AA5754+2.5AA6008T61 joints with the DC die and the DF die, respectively. Figure 15 shows that all specimens with the DC die before and after corrosion failed in the bottom sheet at locations close to the edge of joint buttons at all load amplitudes tested. However, from Figure 16, it can be seen that for specimens with the DF die, they could fail in the bottom sheet around the edge of the joint button or from both the top and bottom sheets around the edge of the punched hole and the joint button, depending on the load amplitudes applied. Before corrosion, specimens with the DF die failed from the bottom sheet at the low and medium load amplitudes (1.26 and $2.025 \mathrm{kN}$ ), and they failed from both the top and bottom sheets at the high load amplitude $(2.7 \mathrm{kN})$. After corrosion, specimens with the DF die also failed from the bottom sheet at the low load amplitude $(1.26 \mathrm{kN})$, but the specimens started to fail from both the top and bottom sheets at the medium load amplitude $(2.025 \mathrm{kN})$ and the high load amplitudes $(2.7 \mathrm{kN})$. Previous research from $\mathrm{Li}$ et al. [11, 15] showed that for the specimens that failed in the bottom sheet around the edge of the joint button, cracks would initiate at the top surface of the bottom sheet at the edge of the punched hole; for the specimens that failed the top sheet around the edge of the punched hole, cracks initiated at the bottom surface of the top sheet, roughly underneath the outer ring of rivet head, and then developed in transverse direction and along the sheet thickness direction to the top surface of the top sheet.

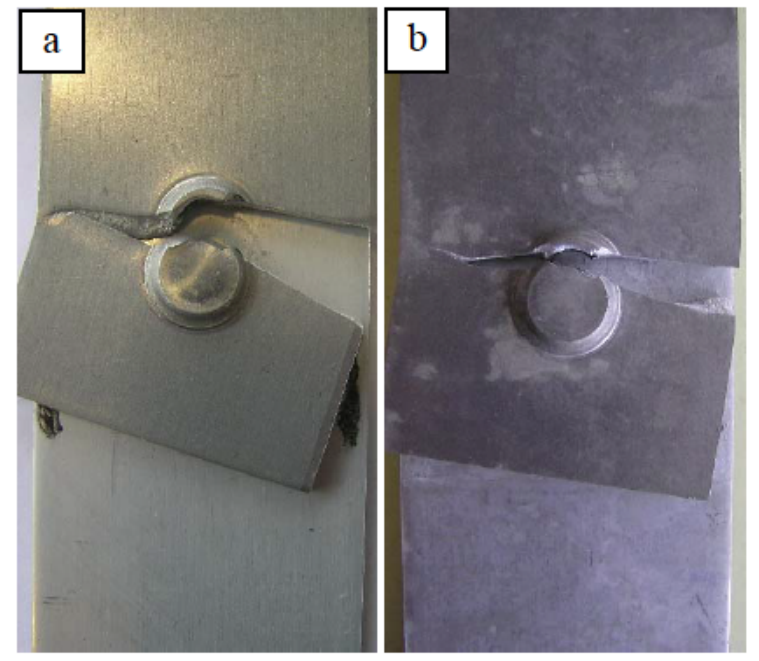

Figure 15: Representative fatigue lap shear fracture interfaces at all load amplitudes tested for the stack of 2.5AA5754+2.5AA6008T61 with the DC die, a) before corrosion, b) after corrosion.

For the specimens studied, during the static tests, all joints failed from the mechanical interlocks: with rivet being pulled out either from the top sheet or the bottom sheet. However, during the fatigue tests, all joints failed from the substrate materials: the top sheet or the bottom sheet, and the crack initiation and development in the substrate materials was determining the joint fatigue life. From Figures 14-16, it can be seen that although there was corrosion on the substrate materials, especially at the top and bottom sheet overlapping area, due to galvanic and crevice corrosion, the corrosion on the aluminium alloys was not severe and its influence on the fatigue life was not significant.

\section{CONCLUSIONS}

In this paper, the mechanical strength of four stack/die combinations with different joint button cracking severity was studied before and after salt- 

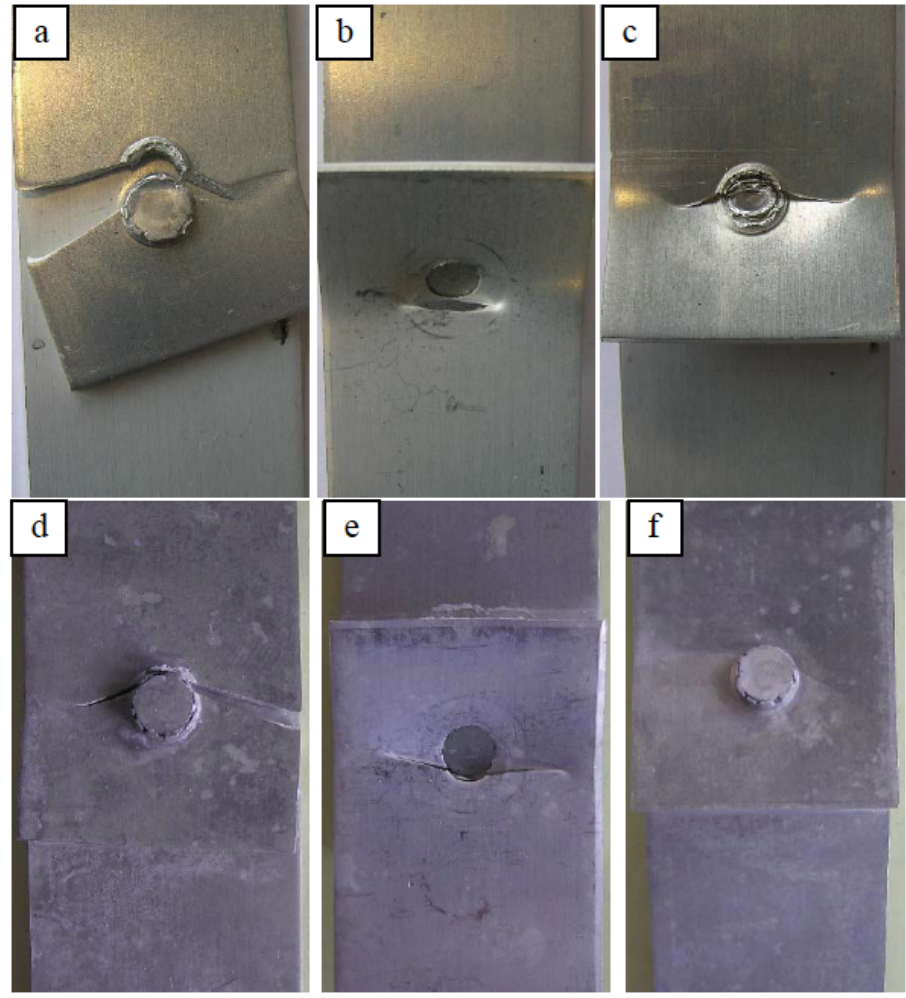

Figure 16: Representative lap shear fatigue fracture interfaces at different load amplitudes for the stack of 2.5AA5754+2.5AA6008T61 with the DF die before corrosion (a, b, c) and after corrosion (d, e, f), a) load amplitude at 1.26 or $2.025 \mathrm{kN}, \mathbf{b})$ c) front and back, load amplitude at $2.7 \mathrm{kN}, \mathbf{d}$ ) load amplitude at $1.26 \mathrm{kN}, \mathbf{e})$ f), front and back, load amplitude at 2.025 or $2.7 \mathrm{kN}$.

spray corrosion test, and the following conclusions can be drawn:

1. AA6008T61 has a cracking issue when it is joined as the bottom material by SPR. When a DF die with deep cavity and sharp corner was used, severe cracks were generated at the joint buttons. However, a DC die with shallow cavity and tilted side-wall could reduce the deformation of the bottom sheet and subsequently greatly improve the cracking issue.

2. The corrosion on the severely cracked joints was worse than that on the joints with small cracks, because the corrosion media could reach the rivet/bottom sheet interface. The results also showed thatthe corrosion on the stack with the same top and bottom material was less than that on the stack with different top and bottom materials, due to additional galvanic corrosion caused by different corrosion potentials.

3. For all joints, the static lap shear strength after corrosion were improved due to the tighter joints and increased local friction caused by the corrosion and corrosion products, but the static $T$ peel strength after corrosion were slightly reduced or did not have obvious change.

4. The results also showed that after corrosion the lap shear fatigue strength of the specimens with severe cracks did not have obvious change, but the lap shear fatigue strength of the specimens with small cracks slightly reduced.

\section{ACKNOWLEDGEMENT}

The authors would like to thank the European Regional Development Fund, the Advanced West Midlands Fund, and the HVM Catapult from Innovate UK for the support of this research.

\section{REFERENCES}

[1] Sun X, EV. Stephens and MA. Khaleel, Fatigue behaviors of self-piercing rivets joining similar and dissimilar sheet metals. International Journal of Fatigue, 2007; 29(2): p. 370-386. https://doi.org/10.1016/j.ijfatigue.2006.02.054

[2] Booth GS, et al., Self-piercing riveted joints and resistance spot welded joints in steel and aluminium in SAE Technical Paper. 2000/01. p. 2681.

[3] Krause AR and ARA. Chernenkoff, A comparative study of the fatigue behaviour of spot welded and mechanically fastened aluminium joints, in SAE Technical Paper. 1995; $p$. 


\section{0.}

[4] Calabrese L. et al., Durability on alternate immersion test of self-piercing riveting aluminium joint. Materials \& Design, 2013; 46(0): p. 849-856. https://doi.org/10.1016/j.matdes.2012.11.016

[5] Calabrese L. et al., Failure behaviour of SPR joints after salt spray test. Engineering Structures, 2015; 82(0): p. 33-43. https://doi.org/10.1016/j.engstruct.2014.10.020

[6] Calabrese L. et al., Effect of Galvanic corrosion on durability of aluminium/steel self-piercing rivet joints. Corrosion Engineering Science and Technology, 2015; 50(1): p. 10-17. https://doi.org/10.1179/1743278214Y.0000000168

[7] Mizukoshi $\mathrm{H}$ and $\mathrm{H}$. Okada, Fatigue properties of mechanical fastening joints. Materials Science Forum, 1997; 242: p. 231238.

https://doi.org/10.4028/www.scientific.net/MSF.242.231

[8] Chrysanthou, A., Corrosion behaviour of self-piercing riveted joints, in Self-Piercing Riveting: Properties, Processes and Applications. 2014; p. 41-55. https://doi.org/10.1533/9780857098849.1.41

[9] Ioannou J. Mechanical behaviour and corrosion of interstitialfree steel to aluminium alloy self-piercing riveted joints, $\mathrm{PhD}$ thesis, in School of Engineering and Technology. 2009, University of Hertfordshire, UK.

[10] Howard RM and SP. Sunday, The corrosion performance of steel self-piercing rivets when used with aluminum components, in SAE World Congress. 1983; Paper No. 831816.

https://doi.org/10.4271/831816

[11] Li D et al., The influence of fatigue on the stiffness and remaining static strength of self-piercing riveted aluminium joints. Materials \& Design, 2014; 54(0): p. 301-314. https://doi.org/10.1016/j.matdes.2013.08.072

[12] Li D. Influence of aluminium sheet surface modification on the self-piercing riveting process and the joint static lap shear strength. The International Journal of Advanced Manufacturing Technology, 2017. https://doi.org/10.1007/s00170-017-0710-6

[13] Li D. Influence of local surface texture by tool impression on the self-piercing riveting process and the static lap shear strength. Journal of Manufacturing Processes, 2017; 29: p. 298-309.

https://doi.org/10.1016/j.jmapro.2017.08.003

[14] Li D. et al., Self-piercing riveting-a review. The International Journal of Advanced Manufacturing Technology, 2017; 92(5): p. $1777-1824$ https://doi.org/10.1007/s00170-017-0156-x

[15] Li D. et al., Influence of rivet to sheet edge distance on fatigue strength of self-piercing riveted aluminium joints. Materials Science and Engineering: A, 2012; 558(0): p. 242252.

https://doi.org/10.1016/j.msea.2012.07.119.

DOI: http://dx.doi.org/10.31875/2410-4701.2018.05.4

(c) 2018 Dezhi Li et al.; Zeal Press.

This is an open access article licensed under the terms of the Creative Commons Attribution Non-Commercial License

(http://creativecommons.org/licenses/by-nc/3.0/), which permits unrestricted, non-commercial use, distribution and reproduction in any medium, provided the work is properly cited. 